\title{
Social acceptance of negotiation support systems: scenario-based exploration with focus groups and online survey
}

\author{
Alina Pommeranz • Pascal Wiggers • \\ Willem-Paul Brinkman • Catholijn M. Jonker
}

Received: 28 January 2011/ Accepted: 9 May 2011

(C) The Author(s) 2011. This article is published with open access at Springerlink.com

\begin{abstract}
We investigate people's attitudes toward the possible use of negotiation support systems (NSS) in different social contexts and the consequences for their design. To explore functional requirements and social acceptance in different use contexts, we followed a threestep approach. In the first step, we conducted a number of focus groups with negotiation experts. Second, we conducted focus groups with potential users. The focus groups were a qualitative exploration of people's ideas about NSS that led to design guidelines for mobile NSS. Third, we conducted an online survey (a) to find out in which situations people consider a mobile NSS socially acceptable, (b) to find the factors and relationships that influence this acceptance in the different situations and social contexts, and (c) to investigate the consequences of people's attitudes toward NSS for the system's design. The data showed that subjective norm is an important factor influencing the intention to use the system and that the acceptance of NSS depends on the use context. Therefore, we argue that NSS should be designed not only merely as tools being used in the actual negotiation but also as social devices harnessing social networks to provide support in all negotiation phases.
\end{abstract}

\footnotetext{
A. Pommeranz $(\bowtie) \cdot$ P. Wiggers · W.-P. Brinkman .

C. M. Jonker

Mekelweg 4, 2628CD Delft, The Netherlands

e-mail: a.pommeranz@tudelft.nl

P. Wiggers

e-mail: p.wiggers@tudelft.nl

W.-P. Brinkman

e-mail: w.p.brinkman@tudelft.nl

C. M. Jonker

e-mail: c.m.jonker@tudelft.nl
}

Keywords Social acceptance - Negotiation support systems · Functional requirements - Focus groups · Technology acceptance model

\section{Introduction}

A skillful negotiator has to carefully balance the issues at stake, have a good understanding of his own and the opponent's needs and since negotiation is a social activity, manage relationships and handle emotions (Thomson 2005). Often negotiating involves overlooking a vast amount of options, deciding on strategies and evaluating bids with multiple attributes. Computational power can facilitate these processes. Within different research areas, e.g., management science, e-commerce, and artificial intelligence (Kersten and Lai 2007; Rangaswamy and Shell 1997; Schoop et al. 2001; Vetschera et al. 2006), researchers have worked on systems supporting people electronically in negotiations. Existing negotiation support systems (NSS) can significantly improve the human performance in negotiations and increase the number of win-win outcomes if the negotiation space is well understood (Hindriks and Jonker 2008; Kersten and Lo 2003).

Despite these advantages that NSS can offer especially to the unexperienced negotiator, the majority of existing (NSS) are not only used in real-life practice, but used only for research and training purposes (Kersten 1999). One reason for this problem may be the technical focus that is prevailing in current NSS development and thereby lacking to address social issues and human factors in the design. We believe that a user-centered design process is the key to understanding such issues and designing solutions that will be accepted by the intended target users. 
Another reason may be that current NSS are developed as stand-alone applications (Kersten and Lai 2007) or webbased applications (Kersten and Lo 2003) and thereby lack in their ability to be applied in real-life negotiation contexts. Negotiation, however, is an activity that can take place in almost any setting instead of being tied to, e.g., an office, and therefore, NSS should be designed to support people in these different settings. Imagine a negotiating for buying a new house. Part of this negotiation is, e.g., collecting information about different neighborhoods; it involves visiting houses, discussing things with the owners etc. These actions take place in different settings, and a NSS should be able to collect the data in these contexts, store them all in a central place, and be able to give realtime advice in these settings based on what has been stored earlier.

The advance of mobile technology, especially the recent developments in smartphone technology and usage, opens up a whole new range of possibilities to make this possible. Mobile technology can enable people to have their NSS at hand in any negotiation phase (including the preparation) independent from place and time. Devices such as smartphones, mobile phones, PDAs, or handheld computers offer, e.g., opportunities to store and compute large amounts of data, access online sources, and show graphical data on color screens. Smartphones are additionally equipped with sensors such as GPS, microphones, and cameras that can be employed to capture context and offer intelligent functionality (e.g., sensing the level of aggression during a conversation). The number and diversity of people using portable internet devices is rapidly growing (ITU 2004), which makes mobile NSS even more feasible and attractive to a wide population of users.

We would like to take advantage of these trends and develop a new kind of NSS for mobile use, a so-called Pocket Negotiator (PN) as described by Hindriks and Jonker (2008). Our vision is to develop a mobile system that can collaborate with unexperienced negotiators in order to reach win-win outcomes in negotiations. The PN will enhance the negotiation skills and performance of the user by increasing the user's capacity for exploration of the negotiation space, i.e., possible bids and deals, reducing cognitive task load and preventing mental errors. The functionality of the device will be focused on handling computational complexity issues and providing bidding and interaction advice. Our idea is to cover all negotiation phases (preparation, joint exploration, bidding, and closure) (Thomson 2005) with support from the system. Generally, such a system could be used in any negotiation domain. We believe it would be especially useful for negotiations with large possible outcome spaces (that are difficult for people to overlook) and important consequences, e.g., real estate or job contract negotiations.
The mobile nature of the system will allow users to refer to the support not only when they prepare themselves at home, but also when they are on the move or even during the face-to-face situation with the other negotiation partner. This entails several advantages. The users can, e.g., collect relevant information for the negotiation and enter it immediately into the NSS or update information about their preferences in case they change due to new information. They can practice the different negotiation steps and review tips and strategies at any time. In a face-to-face situation, it might also be useful to enter information, e.g., revealed by the opponent (i.e., spoken words or information about the opponent's behavior and emotions). Based on this input, the NSS will be able to give context-relevant advice or it could just serve as a reminder for information entered by the user during earlier preparation. Also the possibility of connecting to a wireless network enriches the functionality of the NSS, e.g., by providing online market information.

With this new freedom mobile NSS offer, new questions and problems occur. First of all, the functionality of the system and its interaction with the user need to be carefully designed to fit the mobile settings. In a face-to-face setting, e.g., the user needs to focus mainly on the interaction with the negotiation party and does not have the cognitive resources available to interact, to the same extent. with the NSS. Second, the question of social implications arises. When putting NSS into the social setting of a face-to-face negotiation or using it in public spaces, we have to consider appropriateness and acceptance regarding the user, the opponent, or bystanders. Entering information or consulting the NSS during a negotiation might interrupt the flow of the communication or bother the opponent for other reasons. Furthermore, the user might be concerned about his or her image when using a mobile NSS in public. These are issues worthwhile investigating.

Currently, the use of NSS is rather focused on preparation than on the actual negotiation, as further explained in the next section. We believe that in order to design NSS that will be successfully used in negotiations, we need a human-centered approach investigating the attitudes people have toward NSS, especially given different use contexts. Our main goals are to elicit functional requirements from experts and potential users and to investigate the acceptance of NSS in different social settings.

The paper is structured as follows. Section 2 gives an overview of existing work in the area of NSS and acceptance of mobile devices and services. Section 3 explains our overall approach to eliciting requirements and understanding acceptance of NSS in different contexts. This approach is described in detail in the next sections, including developed scenarios of NSS use (Sect. 4), expert focus groups (Sect. 5), user focus groups (Sect. 6), and a 
social acceptance survey (Sect. 7). The results from the survey are explained in Sect. 8, followed by possible design implications from the focus groups (design guidelines) and the survey (Sect. 9). Finally, conclusions drawn from our work are presented in Sect. 10.

\section{Related work}

\subsection{Existing NSS}

In a recent review, Kersten and Lai (2007) give a detailed overview of NSS and E-negotiation systems. Among other things, they give a categorization of software systems and a structure of key constructs used in NSS. An NSS developed by Kersten and used mainly for training and teaching is the Inspire system (Kersten 2004). The system employs a 3-phase model including pre-negotiation, negotiation, and post-settlements. Kersten and Lai conclude that rather few systems were successfully used in real negotiations. The majority of existing NSS has been used for training and research purposes but has not been applied to real-life negotiations (Kersten 1999). A recent study on user acceptance of web-based NSS (Vetschera et al. 2006) predicts that 80 percent of the users would use the system to prepare and train for negotiations but only 61 percent would use it in the negotiation. Why is the acceptance for real cases so low?

One possible answer is that NSS development concentrates on technological solutions, while the social problems they intend to solve are secondary or completely neglected (Bui 1994). Negotiation is inherently a social activity, since it involves communication between at least two parties and is influenced by the social setting in which it takes place. Literature on business science (Havard Business School Essentials 2003) has, e.g., emphasized the influence of relationships on negotiation processes. Swaab et al. (2004) argue for a careful analysis of social and psychological processes in order to design good NSS and claim that the success of an NSS depends on the understanding of the activity that the system will support. They primarily look at two aspects that influence the outcomes of negotiations positively, namely common (cultural) identity and shared cognition. In this sense, NSS can help by providing information to the opposing parties to establish a common understanding of the problem and possible solutions. Their studies show that the nature and representation of the information can influence negotiation outcomes.

Another effort to emphasize the importance of social and also emotional issues in negotiation and their consideration for NSS has been made by Bui (1994). In his article, the author points out problems that evolve from the fact that empirical research focuses only on the rational aspects of negotiation. For instance, the negotiation models that are implemented in NSS assuming strict economic rationalization ignore that people also take decisions based on social acceptability of different means to achieve a deal. Adding reasoning based on ethical and social norms to negotiation models will allow them to better represent the real-life negotiation processes. Bui explores socioemotional aspects such as conflict awareness, thoughts, emotions, intentions, trust, and norms and their impact on negotiation. He creates a general list of aspects that NSS should help users with identifying controversy, clarifying issues/criteria, equalizing parties or finding solutions, and simulating impacts of potential decision. These can be seen as more generic guidelines for the functionality and design of NSS. These works (Bui 1994; Swaab et al. 2004) refer to shared NSS used either collaboratively by all parties or as mediators. This is one type of NSS with special requirements. An interesting related research area where social aspects are, however, considered is the design of group decision support systems (Nunamaker et al. 1996). However, also in this research, the focus is on collaboration and verbal communication between the participants rather than other social aspects such as context, thoughts, emotions, or trust.

\subsection{Social impacts of mobile technology}

Researchers focusing on the adoption of mobile technology, in general, have recently included social context into their models. Social impacts of mobile technology have been widely studied (Ling 1997; Love and Perry 2004; Mallat et al. 2009; Palen et al. 2001), especially the pervasive nature of mobile phones in public places. Most of the literature in this area focuses on the distraction of bystanders by people talking loudly on the phone or by the mix-up of geographic spaces (current physical space the mobile phone user is in and the space created by a phone conversation) (Ling 1997; Love and Perry 2004; Srivastava 2005). In the case of using a mobile NSS, distraction is, of course, especially an issue when the NSS user is in an active, ongoing communication with the other negotiation party (face-to-face or on the phone). The interaction with the device might disrupt this communication and therefore be less socially acceptable. Furthermore, the other party might not accept the interaction with the NSS because it allows the user to have an advantage and other party might feel excluded. In other situations where the NSS is used for preparation, social acceptance might be less of an issue.

\section{Overall approach}

We aim to build a NSS that supports people that are nonprofessional negotiators (novices) and may have different 
levels of negotiation experience. To explore functional requirements and social acceptance in different use contexts, we followed a scenario-based approach including three main steps: expert focus groups, user focus groups, and an online survey. Although we aim at novices, we did expert focus groups because they allowed us to grasp common pitfalls in negotiations that novices may not even be aware of. Since we are in the early stages of designing a $\mathrm{PN}$, we do not have a running prototype at this stage. To be able to communicate our vision of a mobile NSS, which could be used in different contexts, we created a number of scenarios. Each scenario represents a use situation with distinct characteristics (see Sect. 4.1). In order to emphasize the different design decisions made while writing the scenarios, we did a claims analysis. These claims were used as a basis for short questionnaires used in the focus groups. We created storyboards and short films to visualize the scenarios. These films were used in all three steps of our approach. In the first step, we conducted a number of focus groups with negotiation experts. With their expert knowledge, we expected to be able to get insights into common negotiation practices and problems people face, which could be addressed by the functionality of our NSS. Therefore, the focus was on the functional aspects. Second, we conducted focus groups with potential users, i.e., people with various levels of negotiation experience excluding experts. The focus in those discussions was the social acceptance. Focus groups deliver a lot of qualitative data, which is difficult to draw general conclusions from. Therefore, in the third step, we conducted an empirical study of social acceptance. We designed an online survey (a) to find out in which situations people consider a mobile NSS socially acceptable, (b) to find the factors and relationships that influence this acceptance in the different situations and social contexts, and (c) to investigate the consequences of people's attitudes toward NSS for their design. In the following sections, we describe the steps in detail.

\section{Scenarios of use contexts}

Before designing the concrete functionality of a PN and implementing first prototypes, we would like to investigate the attitudes toward mobile NSS in different situations. This will enable us, on the one hand, to inform the further design process and, on the other hand, find answers to why current NSS are not used in real negotiations. To be able to give the experts and users an idea of our envisioned system and possible use contexts nevertheless, we used filmed scenarios in the focus groups and the online survey. In the following sections, we will first describe the development of five scenarios representing different use contexts.

\subsection{Scenarios}

Scenarios are useful in the design process since they capture the consequences and trade-offs of designs (Carroll 2000). The narrative nature of scenarios enables users to imagine the use situations and contexts of new or existing technology. In the project, we currently focus on two example domains for NSS use: job contract and real estate negotiations. In order to capture all possible contextual factors in a number of scenarios, we identified important dimensions for NSS use in a brainstorming session with the project group. These dimensions include:

1. Presence of an opponent, i.e., whether the user is communicating with an opponent while using the NSS. This can be either face-to-face or remote communication (e.g., phone, internet).

2. Number of users. Although the PN is meant to support one party in a negotiation, there can be a single user or a number of users (e.g., a couple) forming a party.

3. Mobility. The NSS can be used either at home or at work or while being mobile (e.g., on a train).

4. Mode of NSS use. The NSS can be used openly, i.e., the opponent knows about it, or in stealth mode, i.e., the opponent is unaware of the NSS use.

5. Negotiation phases, i.e., preparation, exploration, bidding, and closure. For the scenarios, we mainly distinguish between preparation, which is typically done by the user alone, and the last three phases that involve interaction with the other party.

Combining all of this dimensions would lead to a high number of use contexts. Therefore, we created meaningful combinations to be able to reveal all aspects and discuss them with our participants. We chose two use contexts illustrating a job negotiation: short preparation being mobile on a train and face-to-face with the boss with concealed use of the NSS. Two scenarios had real estate content: distant negotiation on the phone and collaborative preparation of a couple. The last one illustrated a situation face-to-face with open use at a car dealer.

For each of the five use contexts (Fig. 1), we wrote a scenario presented in the following in summary. All scenarios were checked by a professional negotiation coach to make sure that they were sufficiently realistic. Each scenario is briefly discussed below. Italic text is taken from the original texts of the scenarios.

Mobile Preparation with Time Constraints (train) Preparation is one of the negotiation phases stressed in the literature, e.g., (Havard Business School Essentials 2003). In this scenario, we describe a preparation situation with special constraints. The job applicant Martin is already on his way to the interview. Therefore, he has limited time to prepare himself. In addition, the mobile setting constitutes 

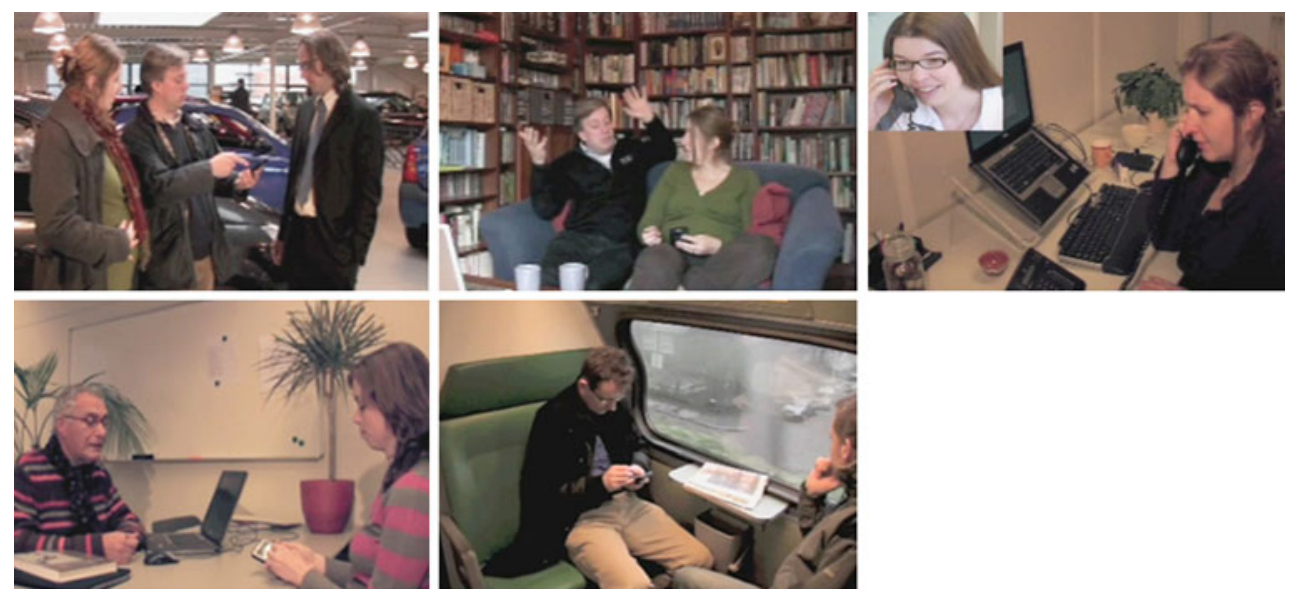

Fig. 1 Scenarios (Screenshots from videos) from left to right, top row: open use at car dealer, collaborative preparation before buying a house, on the phone with real estate agent; bottom row: evaluation talk with boss, preparation for job interview on the train

another constraint, namely limited resources. Both constraints require special regard when it comes to the functionality of the device. Just before getting on the train, Martin has received a mobile NSS from a friend. He uses the device's speed preparation function to prepare himself in the short time he has left. Among other functions, the device allows him to receive knowledge about the job negotiation domain.

He wonders how much money he could ask for. He chooses 'expert opinion' on the interface and types in 'salary'. The PN suggests a website that has a forum where you can discuss current average salaries for IT-consultants with an expert in the field. After reading through the forum Martin has a quite good idea what he can ask for with his kind of educational background and experience. With that knowledge he feels more secure and relieved.

Later in the scenario, Martin makes use of the training module of the NSS which enables him to go through a simulated interview with a virtual agent. He receives onthe-fly advice about his and the opponent's actions. The scenario ends with Martin being more relaxed, knowing what to expect in the upcoming negotiation.

Face-to-Face Negotiation, Secret Use (F-2-F). The situation described in this scenario is a negotiation between an employee, Bianca, and her boss. Bianca is using a mobile NSS. The emphasis in this scenario is the concealed use of the NSS. Bianca is hiding the fact that she has support from an NSS by telling her boss she is using her device only to take notes.

Bianca has been working for a big telecommunication company in The Hague for 2 years now. Today her annual evaluation with her boss is due. Bianca wants to take this meeting as an opportunity to re-negotiate some parts of her contract. Since her husband got a new job in another city, they decided to move further away. Therefore, she wants to discuss opportunities with her boss to handle the new situation. She knows that she worked hard and well in the last year and should get what she wants, but she does not consider herself a good negotiator. Therefore, she recently got the $P N$ and prepared herself for this negotiation with the device.

Throughout the negotiation described in the scenario, Bianca receives help from the device. Several functions are described in this scenario including the management of emotions, generating new options, and receiving advice from the system. The scenario ends with a deal in which both parties gain something and are satisfied with.

Collaborative Preparation (Coll. Preparation). Negotiation involves a lot of emotions not only on both sides of the bargaining table, but also within one party, e.g., between two partners buying a house together. In this case, the first step is to merge the demands and preferences of both partners before starting a negotiation with the opponent side. Our scenario describes a couple that is planning to buy a house together and uses the NSS during the preparation to sort out their preferences and to download domain knowledge about real estate.

The 'collaborative preparation' module starts up. After a short introduction the PN asks each of them to put in their preferences for a house separately. Since they also have the PN software installed on their laptop they put in their preferences in parallel. From both preference profiles the PN creates a matching profile and shows the clashes of their preferences. It advices the couple discussing the clashes and trying to find trade-offs between them that suit both. 
During this process of compromising, the couple gets into a quarrel in which both insist on their own wishes without even communicating the underlying reasons in detail. In this case, our device takes on a proactive role and interrupts the couple to give advice on how to handle the conflict.

The PN senses the noise and the angry voices in the room and assumes an argument. The PN suggests calming down[... and...] prompts them to put in an emotional value on a scale from 'I don't care at all' to 'I would die for this' for each variable they have different preferences on.

After having sorted out all their preferences, they start looking for houses. In the last scene of the scenario, the couple visits a house and takes advantage of the PN's feature of taking pictures and storing them together with other information about the house in a database.

Negotiation on the phone (Phone). A negotiation in which both parties are not situated in a face-to-face setting but are distant from each other offers different design challenges for a NSS. First of all, one party does not see the other party, and therefore, the use of a NSS can take place without each others' notice. In real estate situations especially, e.g., when buying a house, another aspect to consider is that the negotiation is split into a number of phone calls. This gives the user time in between the calls to use the system in each step of the negotiation. Our scenario describes a couple negotiating for a house. Before the interaction with the opponent, they prepare themselves with the help of the NSS.

Furthermore, the PN has downloaded housing domain knowledge, such as contracts and legal issues and the prices of similar houses in the neighborhood to take into account. Before Mary came to work this morning she had decided with Piet to set a first bid around 450.000 Euro.

At work, Mary calls the agent and starts negotiating. Before and during the phone calls, she uses the NSS on her laptop to receive advice about different steps in the negotiation, e.g., the PN advises her to not start the negotiation with offering a price, but instead talk about other issues and options.

The bidding goes on for a while and the PN shows a visualization of the bids in the outcome space based on the preferences of Piet and Mary and the estimated preferences of the agent. After a while the PN detects that the bidding is not reaching a winwin situation.
After finding new variables to include in the negotiation to reach an agreement that suits both parties, they finally close a deal.

Face-to-Face Negotiation, Open Use (Car Dealer). We decided to include another scenario that has a face-to-face setting, but showing an open use of the NSS meaning that the other party is aware of the use. This scenario is about a couple buying a car. Our belief is that the car dealer's setting enables people to use the NSS more openly. When buying a car, it is usually not necessary to stick to one specific car dealer. No long-term relationship needs to be considered. Therefore, the couple in the scenario openly states that they will be using the NSS and explain what they can do with it.

The focus of the scenario lies in the advice of time-outs at strategic points during the negotiation. During the process of looking at cars and refining their preferences for the new car, they enter information about the state of the negotiation into the NSS. They receive strategic advice on how to proceed and when to take the time to recapitulate.

He [the car dealer] shows them a range of more sporty looking family cars and the couple chooses

their favorite. They enter that into the PN. The PN

advices them to take a time-out and check whether

they have considered all their preferences and whe-

ther all the information they need has been disclosed.

After they have found an interesting car, the bidding starts in the car salesman's office. The NSS assists the couple by comparing prices with similar cars online. They disclose to the salesman that the market price is lower than his offer. The salesman drops his price. They negotiate about a few extras and finally leave with a new car and a deal they are satisfied with.

\subsection{Storyboards and videos}

Due to their illustrative strength, scenarios are a good means to communicate design ideas within the project team as well as to users or experts in the field. In order to exploit that strength even more, we decided to visualize the scenarios. First, we created a storyboard (Fig. 2) for each of the scenarios. These storyboards then served as a basis for the shooting and editing of short (about 2-3 min) videos (see http://mmi.tudelft.nl/negotiation/index.php/Media for videos (in Dutch) and complete English storyboards per scenario). Using videos, we were able to present the use contexts of our NSS very well. Much of the functionality of the NSS was kept open for interpretation to avoid limiting the discussion about the functionality. 


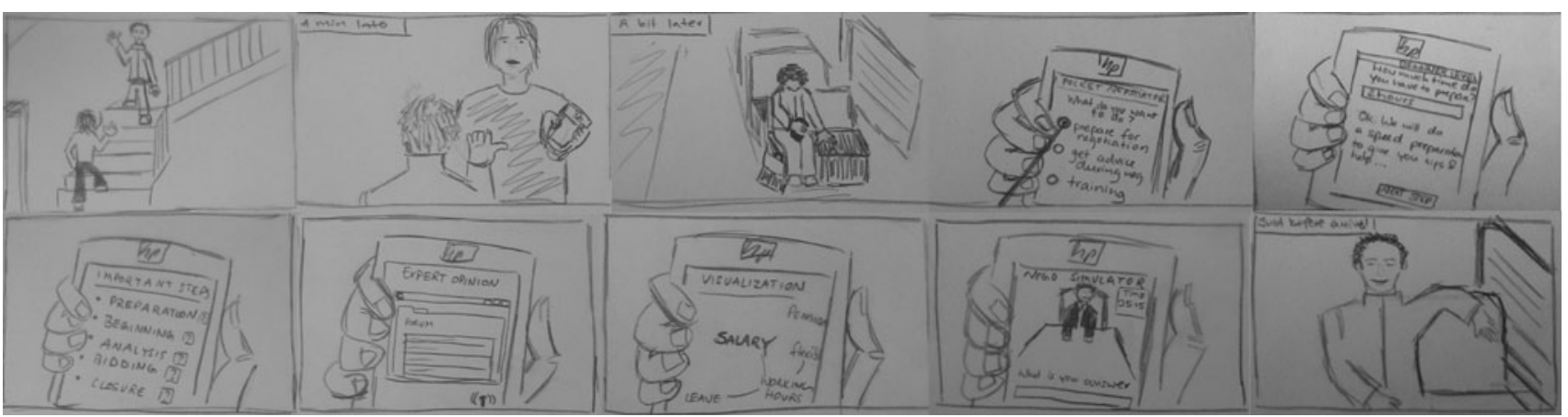

Fig. 2 Storyboard for scenario: mobile preparation with time constraints (train)

\subsection{Claims analysis}

Due to the scenarios' narrative nature, many things are left implicit. Often causal facts and relations underlying the actions described are not revealed. Therefore, it is useful to enumerate such causal relations separately. This can be done through claims analysis (Carroll 2000). Each claim underlying a certain action or design feature in the scenario is listed together with its tradeoffs. We used the claims as proposed by Neerincx (2003), i.e., to test our hypothesis about functionality and use contexts in the focus groups discussions with the experts. We wrote down four to six claims per scenario based on our hypothesis. Due to space limitations, we cannot list all the claims here, but only give examples. The first claim was written for the face-to-face scenario with the boss and the second for the negotiation on the phone scenario:

Advice claim the NSS gives generic advice for different negotiation phases in a text-based form (e.g., ask for reason of concern, be sympathetic, and maintain the relationship).

+ Even though the user might know of such things due to a good preparation, the NSS advice serves as a reminder during the negotiation process.

- The user might not be able to put the advice to practice or the way he tries to do so is not effective.

Graphical representation claim the NSS shows the current status of the negotiation graphically including all variables.

+ The variables and their influences on the negotiation process are shown, so that the user can understand the process better.

+ The user can recapitulate and learn for future negotiations by looking at the current status and the influences of the variables.

- The number of variables and influences is high and the user finds it hard to learn from the graphical representation.

- The graphical representation is not understood by every type of user.

\section{Expert focus groups}

Focus groups (Sim 2001) have been widely used in marketing to exploit the dynamics of group discussions in order to receive attitudes toward ideas or products. Bruseberg and McDonagh-Philp (2002) have shown that focus groups are also useful during the design process of new technologies. They help participants to articulate their ideas and provide the researcher with inspiration for the design process. Lately, HCI researchers have adopted the method and refined the techniques used to stimulate the discussion. As, for instance, Goodman et al. (2004) found out, it is profitable to use visual help such as pictures and also scenarios in focus groups. Furthermore, tasks can start up a discussion. Based on these findings, we used the previously described filmed scenarios in the focus groups.

\subsection{Setup and procedure}

In total, we had 12 experts divided into three focus groups. We divided the experts into different focus groups according to their expertise. As explained by a number of researchers, e.g., (Sim 2001), the homogeneity of the group plays an important role. The more similar the group members are, the more likely they are to voice their opinions. Therefore, we formed one group with general negotiation experts, such as negotiation trainers, lawyers, and a judge, and two with job negotiation experts, such as human resource employees and labor union representatives. In the beginning, participants were introduced to each other and the project was described. Every participant received a questionnaire that contained two claims from the claims analysis (see Sect. 3) per video. The claims, however, were reformulated into statements that allowed the experts to specify their level of agreement with. The two claims named in the previous section were presented as the following statements:

- General tips and strategic advice (e.g., try small talk, show sympathy for your opponents concerns) is more 
useful for the user than specific behavior and decision advice.

- The NSS should focus on helping the user to understand the bidding process (e.g., graphical representation of the bidding including history of bidding) rather than proposing the next bid.

After watching each video, the participants individually specified their level of agreement with each claim on a 7 -point Likert scale and provided comments. We chose this method to give everyone a chance to think about their own attitudes and opinions in silence. As pointed out by, e.g., Carey (1995), less confident members may be encouraged to disclose more when having written down their views in advance.

With regard to the organization of the researchers, we had three researchers present in every focus group session. One was appointed to be the moderator and the other two were observing and taking notes to capture what was happening between the members of the group, but they did not interrupt the flow of the discussion between the participants. We chose for this setup to avoid any influence by the researchers. Once every member finished writing their comments, the moderator started a group discussion, by asking the participants in turn to react to the claims and discuss their ideas with the others. The moderator stimulated the discussion without enforcing any existing views from the project team. The discussion was audio-recorded for later analysis.

\subsection{Results}

Our approach results in two types of data, i.e., qualitative discussion data in form of written notes and quantitative data from the questionnaires. To analyze the questionnaire data (values on a Likert scale), we used a standard mean value calculation. Figure 3 presents the average level of agreement of the experts with the claims that were presented in the questionnaire. Considering the 95 percent confidence interval and the value four as the middle of the scale, the results suggest that the majority of the experts leaned toward agreeing with the following claims: (2) open use of the device when buying a car benefits the outcome; (3) the device should help the user to understand the bidding rather than giving the next bid; (7) general tips are more useful than specific advice; (8) in preference elicitation ask for core concerns (instead of specific values); (9) short training and simulation enhances negotiation skills; and (10) short preparation contributes positively to negotiation outcomes. The qualitative data explain the rationale behind these positions and provide additional ideas.

For the analysis of the qualitative data, we used a method similar to interpretative phenomenological analysis (Smith and Osborn 2003), which is a bottom-up method often used in psychological qualitative research. The idea is to go through the data from one focus group to gather emerging themes from the text. Themes can be recurring ideas, thoughts, or feelings from the participants. These
Fig. 3 Mean values of agreement with claims ( $1=$ strongly disagree,

$7=$ strongly agree)

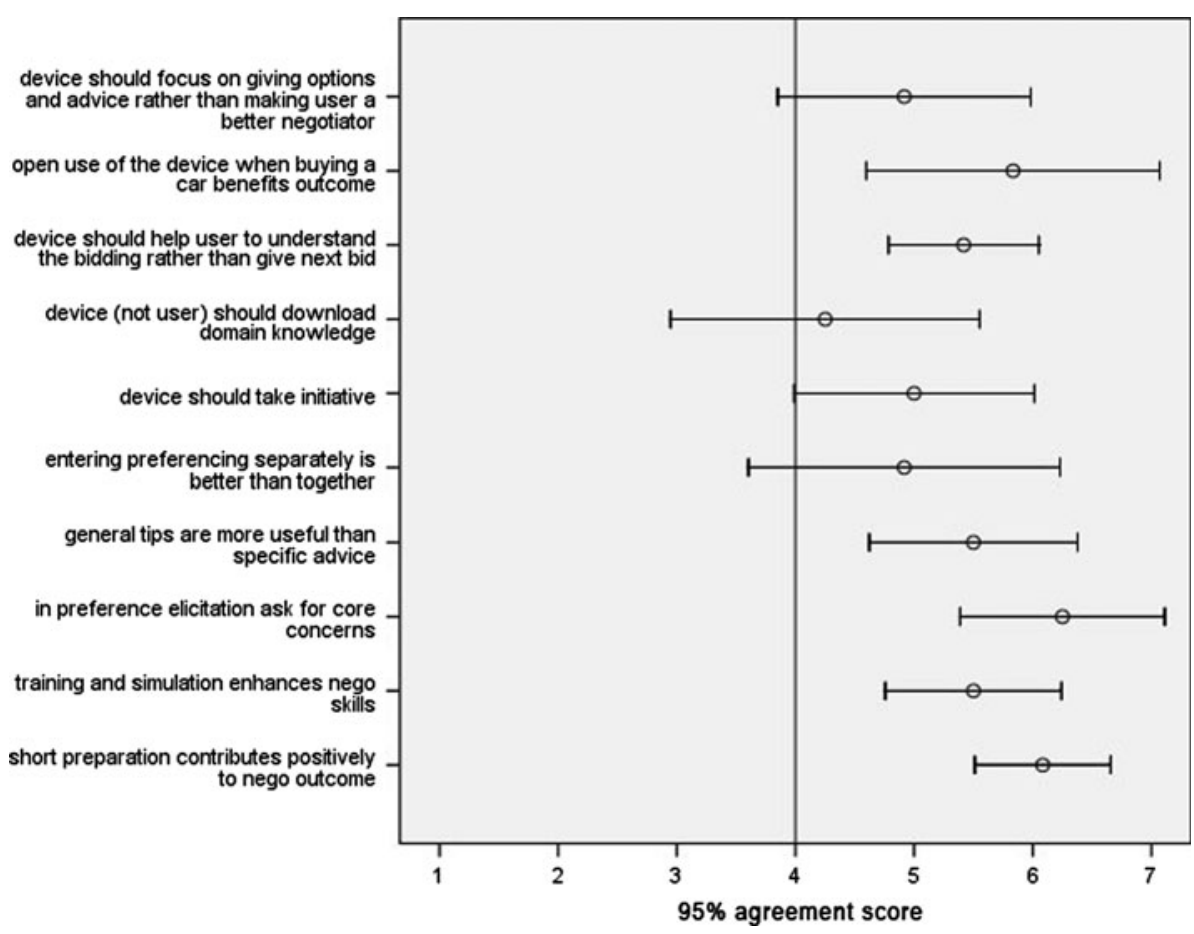


themes are then clustered together and superordinate concepts might emerge. This process is repeated for the other focus groups, and finally, the superordinate themes are compared and converged to final themes or theories, i.e., in our case transformed into design guidelines.

We analyzed the sessions separately on the basis of the notes by at least two researchers. The recordings from the sessions were only used in case the notes were not clear enough or incomplete. Every idea or attitude was written on a post-it note. Repeated ideas were not written down again, as we were not trying to get empirical generality, and furthermore, in groups, people tend to agree with or repeat thoughts and ideas.

To define the general themes that can be transformed into design guidelines, four researchers independently clustered the post-it notes. We intentionally included one researcher unrelated to the project. Therefore, we could compare unbiased data with the data from the project researchers. Themes thus identified were then compared across all focus groups. Several themes came up that provided first ideas about people's attitudes and requirements toward NSS. In the following paragraphs, we present the main themes (bold) from the discussions in detail.

An NSS device adds higher value in the preparation and training phase than during a negotiation. Training needs to be interactive and the NSS needs to react intelligently. All experts across the groups agreed on the fact that any preparation for a negotiation is useful. However, some experts mentioned that a technical device should add more value to the preparation than just reading a book on negotiation. They emphasized the importance of training and simulation and pointed out that the system needs to be able to respond to the user in an intelligent way. In detail, one idea that was mentioned was that the system needs to make people aware of what they can negotiate about. In addition, the system needs to ask questions to the user similar to the ones asked in job negotiations. In one group, it was mentioned that multiple short sessions of preparation might be better than one long one.

In a face-to-face situation, it is hard for the user to focus on both the device and the opponent. Most experts were of the opinion that an NSS should not be used in face-to-face negotiations. The job negotiation experts especially mentioned that the way the applicant or employee presents him/ herself is important as well as focusing on the negotiation partner. While using a device, the interaction with the opponent becomes awkward and might be embarrassing. Furthermore, the experts were concerned that understanding and processing the device's information and advice takes too much time and is too much cognitive load for the user in a face-to-face situation.

The context including atmosphere, non-verbal communication, and emotions plays a major role for the negotiation process. In two focus groups, it was emphasized that especially in job negotiations the non-verbal communication and the atmosphere in the room play an important role. Furthermore, emotions influence the decision-making process and the course of negotiation. This means that the system needs to be able to obtain this context information and take it into account when reasoning about next steps. People are generally better at interpreting emotions, non-verbal communication, and atmosphere than computers. One way of enabling the system to understand the context is to build a context model within the system and let the user enter information about the context during the negotiation. To reduce the data that the user needs to feed into the system, other techniques like emotion recognition or using (e.g., sound) sensors might be a solution.

The NSS is strong in the rational part of a negotiation, by offering new options and for storing and managing data. It should provide domain knowledge in terms of facts that the user can use to persuade. Most experts agreed that the strength of a device would lie in handling the rational part of a negotiation. It can store and manage vast amounts of data, deal with the computational complexity during the bidding, and offer new options to the user. Furthermore, domain knowledge should mainly include facts, such as prices or salaries, which the user can use to persuade his/ her opponent.

Both generic and specific advice is useful but needs to be applied carefully. One of our claims was that generic advice is more useful than specific advice. The attitude toward this claim differed between the experts. Many of them saw a danger in specific advice because if the system cannot sense the context, specific advice is often inappropriate. Generally, both generic and specific advice could be useful but is dependent on the negotiation phase and the capabilities of system and user.

The NSS needs to adapt to the user's behavior and his knowledge or experience. At several points in the discussion, it was mentioned that the system advice or reactions need to be adapted to the experience of the user and his/her behavior. Regarding advice given by the system, it was mentioned that novice users who are not good negotiators should get more specific advice, whereas more advanced users are able to apply more generic advice. During the bidding, the system should adapt its behavior to that of the user and recalculate the next bids in case the user changed his/her strategy.

Interruptions are seen controversial. Time-outs, however, are good. The majority of the experts thought that active interruptions by the system through vibrating and beeping during a tense situation are not useful. The users would either ignore the system or become more upset. However, most experts agreed that time-outs are very 
useful for the reflection of the negotiation process. As the user is not always aware of when to take a time-out, the system should suggest it.

Preferences of collaborating partner's should be put in separately. Across the focus groups, there was a consensus that in the process of generating a preference profile for collaborating partner's, e.g., couples, they should put in the their preferences separately. That avoids that one partner is more dominant than another. In our scenario, we proposed that the system then merges the preferences and shows the clashes to the users. The experts did not agree on doing it this way. They pointed out that showing those clashes triggers arguments between the partners instead of a discussion about underlying values. It is more important that the partners talk about such values and come to a conclusion. The system could also directly suggest solutions. It was also proposed that a user indicates the importance of every preference.

Besides these functionality-oriented themes, the discussions showed that the experts' attitudes toward NSS differed widely and that social contexts might play a role when choosing to use a system or not. Social acceptance became a topic in several groups, although we did not specifically ask for it in the questionnaire. The question especially whether it was acceptable in a face-to-face situation was discussed. One hypothesis was that the social acceptance would correlate with the age group of the users. The experts assumed that younger generations due to growing up in a world of mobile technology are more used to people using mobile devices in public and being interrupted by, e.g., mobile phones. While being a plausible assumption, we were curious to see whether it would be confirmed. Therefore, we conducted focus groups with young people.

\section{User focus groups}

To investigate the attitudes of young people toward mobile NSS, we had focus group discussions with 20 high-school students aged 16-18. In these user focus groups, we shifted the focus from functionality-oriented discussions to the social acceptance of the NSS in the different use contexts.

\subsection{Setup and procedure}

The session was split into two parts, i.e., group discussions in smaller groups and a discussion with all students. We first divided the high-school students into five groups of four students each. We assigned one researcher of our project to each group to act as a moderator and observer. In order not to bias the participant, these researchers were instructed to intervene as little as possible, i.e., only to start the discussion and in cases the discussion stopped. At the same time, they were taking notes for later analysis. Each group watched one of the five scenarios. Every participant received a short questionnaire with three statements. Two focused on the social acceptance: (1) I would use the PN in the situation shown in the video and (2) I think that it is socially acceptable to use a PN in this situation. The third statement addressed a functionality aspect of the particular scenario (similar to expert focus groups). All statements were rated by the participants on a 7-point Likert scale $(1=$ totally disagree, $7=$ totally agree $)$ after watching the video. Before starting the discussions, the moderator asked every participant to explain their ratings. Group discussions in the small groups lasted about $15 \mathrm{~min}$.

At the beginning of second part of the session, we asked one group member from every group to explain the situation shown in the discussed video and the main points of the discussion to the other groups. This was done to make sure every participant knew about all five scenarios and could form an opinion about the social acceptability of each of them. Next, a moderator encouraged a discussion between all 20 students, mainly focused on social acceptance, which took about $30 \mathrm{~min}$.

\subsection{Results}

Our initial hypothesis that younger generations think a mobile NSS in public or face-to-face situations is socially acceptable could not be confirmed by the focus groups with high-school students. In the job scenario especially with the boss some students thought a PN would be very strange and unsocial. Others thought that the stealth mode function can be used as a long as the other party does not notice that you have a PN. In any case, it would stop the communication from its natural flow. This would also be the case on the phone. Nevertheless, the students believed it to be more acceptable on the phone, since the other party does not see the NSS. Generally, students tended to see it as more socially acceptable in cases where the other party does not know about the PN. However, if everyone was using a PN, the students thought it would be fine to use one. Overall, we could see that the students were very critical toward the PN and its use. Many emphasized that it is important that the user stays independent from the device instead of following its advice blindly. Furthermore, it is of importance that the advice is presented in a way that is comprehensible to the user. However, the students also saw the strength in a $\mathrm{PN}$. They mentioned that it is helpful in the training and to organize things. Some students believed that insecure people would feel more supported and confident with a PN.

In general, focus groups provide large amounts of qualitative data, due to the dynamic nature of the group and the contextual setting. As discussed in detail in (Carey 
1995; Sim 2001), the data analysis of focus group data is delicate. Researchers have to be aware that focus groups are not meant to find consensus within the group. Therefore, focus groups data are not meant to lead to an empirical generalization but rather give an impression of attitudes of a specific group of people toward a topic or new technology. According to Sim (2001), the data from focus group can provide theoretical insights with sufficient level of universality to be projected to comparable contexts. To complement these initial impressions with empirical data and get a deeper insight into what exactly the influential factors to social acceptance are we designed an online survey.

\section{Social acceptance survey}

From the focus groups, we already got some support for the hypothesis that the use context is influential to the social acceptance. However, other factors were mentioned, such as characteristics of the possible user (age, novice negotiator, etc.), the mode in which the device is used (e.g., stealth mode), or social pressure ("If everyone had a PN it would be okay to use it".). In the following sections, we present a number of research questions that led our design of a questionnaire to investigate the acceptance of mobile NSS. Next, we will describe the underlying model of the questionnaire, the survey, and its results (please see (Pommeranz 2010) for more details).

\subsection{Research questions}

Overall, the question is which are the factors that influence the social acceptance of NSS. We looked at several detailed research questions. RQ1: Is there a relationship between the user characteristics and usefulness, attitude toward negotiation, behavioral control, and social acceptance? The user characteristics include demographic data and experience in computer usage and with negotiations. We expect that age and possibly gender influence the acceptance of a mobile NSS in different situations. In the focus groups, we investigated whether younger people are more open to technology use in public places and social situations than older people because younger generations grow up with technology around them. To get a more definite answer to this question, we also included it in this research. This is reflected in RQ1a: Is there a negative impact of the user's age on the acceptance of a NSS in a face-to-face situation?

Based on the results of the focus groups mentioned and groups with 40 middle-aged women, we expect that people with low negotiation skills and a negative attitude toward negotiation are more likely to use an NSS. Due to their own lack of knowledge about negotiations or insecurity, they might find an NSS more useful than people, who enjoy negotiating and consider themselves good at it. This leads to the questions: RQ2: Is there a negative relationship between a person's attitude toward negotiations and the attitude toward NSS? RQ2a: Is there a relationship between, on the one hand, negotiation skills and experience and, on the other hand, the attitude toward negotiations?

We believe that the acceptance of a NSS in a social context has an impact on the intention to use it. The social acceptance is measured by two variables, one describing how acceptable people find it to use an NSS in a situation (SN 1) and the other describing in how far they believe that the opponent would find it acceptable (SN 2). Whereas in a face-to-face situation, it might play a big role what the opponent thinks, it might become less influential in a phone scenario. Therefore, our last research questions are: $\mathrm{RQ} 3$ : Is there a relationship between the social acceptance of an NSS and the intention to use it? RQ 3a: Does the negotiation situation determine the social acceptance?

\subsection{The model}

To study the social acceptance of mobile NSS empirically, we first developed a model based on existing models and our research questions presented above. This model was the basis for the questionnaire that we used in an online survey.

Since we wanted to predict the intention of people to use a NSS, we could make use of existing, often used models from social psychology and information systems. The Theory of Planned Behavior (TPB), developed by Ajzen (1991), is a well-known model in social psychology to explain the link between attitudes and actual behavior. In this model, the behavior is influenced by the intention to perform the behavior. This intention again has three influential factors, namely the attitude toward the behavior, subjective norm, and perceived behavioral control. Attitude is defined as positive or negative feelings toward performing the behavior. The subjective norm is an individual's perception of others' beliefs whether he or she should perform the behavior. Perceived behavioral control is an individual's perceived ease or difficulty performing the particular behavior. The latter also has an influence on the actual behavior.

Whereas the TPB is a general model predicting behavior, the Technology Acceptance Model (TAM) (Davis 1989) is a more specific model used in information systems research for predicting the acceptance of a technology. The model has been widely used, see e.g., (Wang and Benbasat 2005; Yu et al. 2003), and extended for specific applications (Shih 2004; Wixom and Todd 2005). It identifies perceived usefulness and perceived ease of use as two 
Fig. 4 NSS Social acceptance model

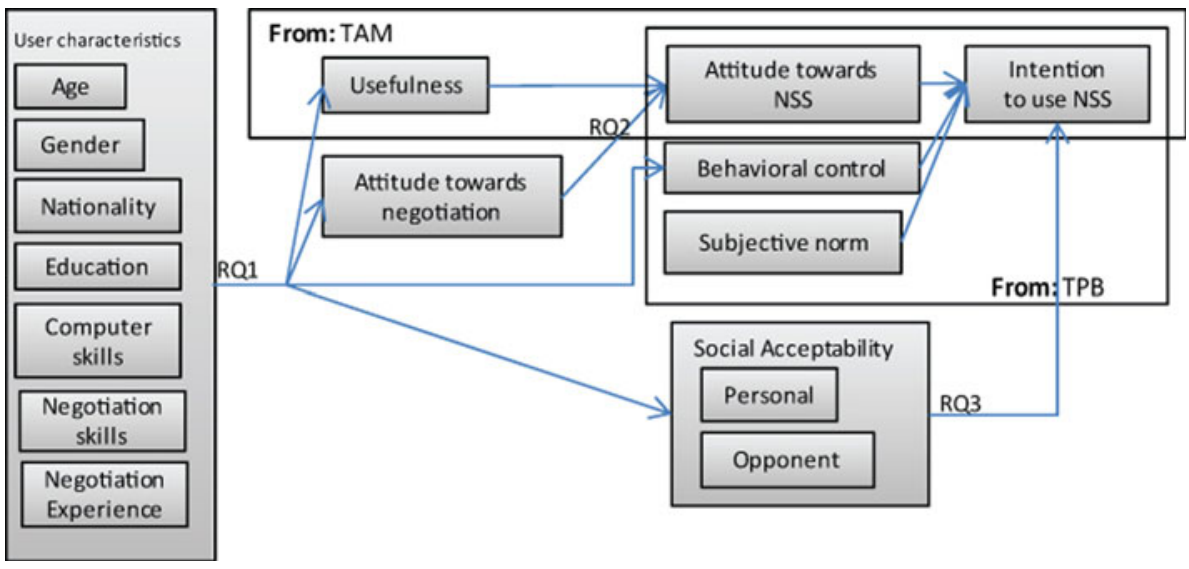

factors that influence the intention to use a system and its actual use. Both TPB and TAM are extensions or adaptations to the Theory of Reasoned Action introduced by Ajzen and Fishbein (1980). Both models predict the actual behavior or use of a system. However, we would like to measure only the intention to use a mobile NSS. In addition, we believe the models need to be extended to fit the more specific negotiation context. Therefore, we used the models as a basis for creating our NSS social acceptance model shown in Fig. 4. In the next section, we will explain how we combined and extended the models in detail.

\subsection{TPB and TAM extended}

Since our study takes place before the implementation of our envisioned NSS and is meant to inform the first designs of it, we are not able to measure the actual use of such a system. Furthermore, other factors that are meant to be perceived by the users, i.e., ease of use, usefulness, and behavioral control, are not easily measurable either. We decided to leave out the ease of use since this can only be experienced during a real interaction with the system. Usefulness and behavioral control, however, are factors that can be measured by providing the users with detailed visualizations of the system's use. Therefore, we showed videos or storyboards of the five scenarios described above. The remaining factors are, therefore, usefulness, attitude toward NSS, behavioral control, subjective norm, and the intention to use the NSS, with their relations taken from the original models as shown in Fig. 4. Based on our research questions, we added a number of factors that might be of influence in the negotiation domain. We added the general attitude toward negotiations as an influential factor of attitude toward NSS. As mentioned earlier, the use of such systems might depend on different situations and how socially acceptable it is to use a system in that situation. Therefore, we added social acceptance as an extra factor influencing the intention to use. Last, we added a number of user characteristics including age, gender, nationality, education, computer, and negotiation skills and experience.

\subsection{The survey}

\subsubsection{The questionnaire structure}

The questionnaire is based on the model shown in Fig. 4. For details about the constructs and questions, see Appendix A. After a short introduction, we collected the user characteristics. The factors intention to use (IU), subjective norm (SN), and social acceptability (SA) were measured after each scenario presented to the respondent. At the end of the survey, we collected more general information about the attitude toward NSS (PNA), including behavioral control (BC) and usefulness (USE). For the majority of questions, we asked the respondents to rate their agreement with a number of statements on a 7-point Likert scale and for an explanation for the ratings after each scenario to explore why people might accept the system in one scenario but not in another.

\subsubsection{Versions}

We setup a Dutch version with short videos (3 min) and a Dutch and English version each with screenshots from the videos and text explaining the situation. The version with videos took about $45 \mathrm{~min}$ to fill in and the picture versions 10-15 min To avoid order effects, we shuffled the order of scenarios and statements.

\subsubsection{Survey distribution and response}

With NetQuestionnaires (http://www.netquestionnaires. com), we administered and distributed the survey online. We used an opportunity sample strategy to select participants for the study. We took advantage of personal networks and online forums to invite people to participate. 


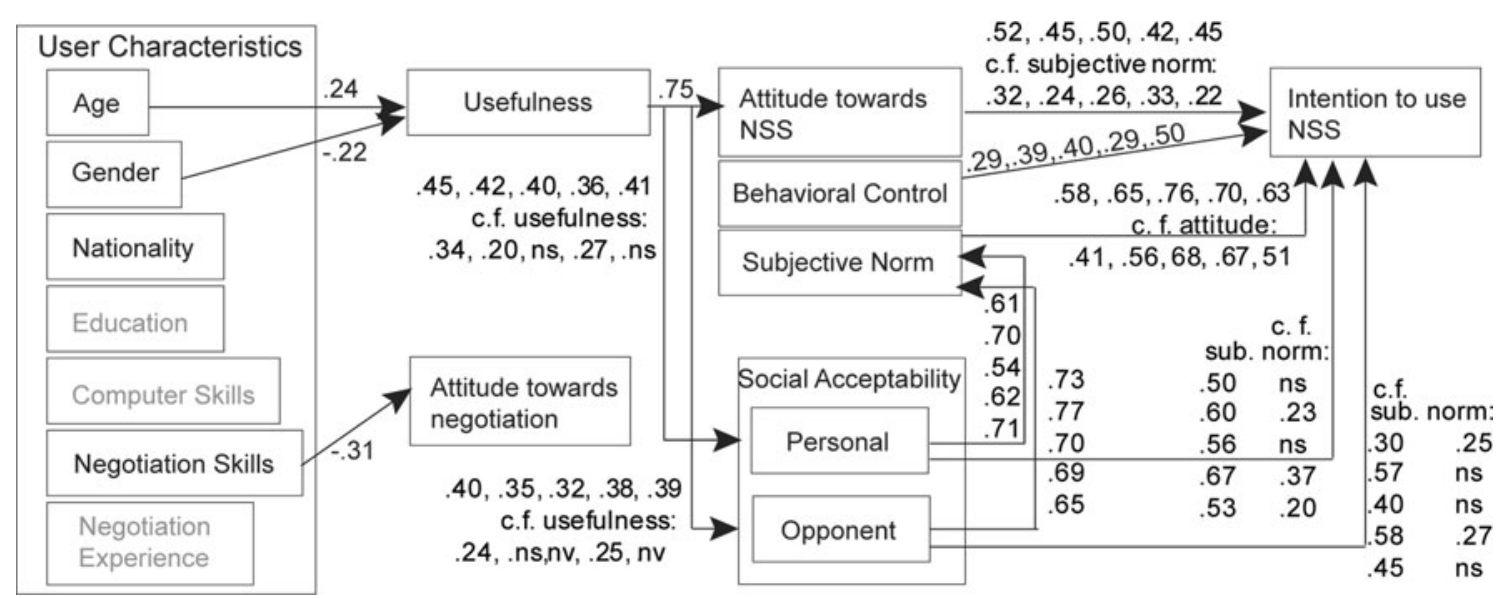

Fig. 5 Model with (partial) correlations, 5 numbers: per scenario, $c f$ controlled for, $n s$ not significant, $n v$ no value

The questionnaire was approached by 365 people. One hundred and seventy-eight started filling in the questionnaire, 120 (74 men, 46 women) from 18 countries completed it, 72, the English, 31, the Dutch version with videos, and 17, with pictures. The most represented countries were the Netherlands (48), Sweden (19), Germany (15), and Greece (10). The age span ranged from 20 to 68 $(\mathrm{M}=32.28, \mathrm{SD}=10.36)$. Participants are mostly familiar with computer usage, with the average number of hours spent at the computer being $44.86(\mathrm{SD}=20.14)$ and highly educated (102 with university degrees). The negotiation experience of the sample is rather low. Only about a fourth of the participants are regularly engaged in negotiations in their jobs (31 participants). On average, participants have bought $0.65 \quad(\mathrm{SD}=0.97)$ and sold 0.47 houses $(\mathrm{SD}=2.43)$ and have had less than seven job interviews $(\mathrm{M}=6.65, \mathrm{SD}=10.33)$.

\section{Survey results}

\subsection{Measurements of constructs}

For an overview of all constructs used in the questionnaire, see "Appendix". We used Cronbach's alpha to test the reliability of the constructs usefulness (USE) (.95) and behavioral control (BC) (.72) and calculated aggregated measures for both including all original items. The Cronbach's alpha for attitude toward negotiation (NAT) including all four original items is very low (.04) but increases to .69 , if the items NAT 1 and NAT 4 are deleted. Therefore, we decided to keep only the items NAT 2 and NAT 3 and combined them to an aggregated measure. For the construct negotiation skills (NSK), we keep the three items NSK 1, NSK 4, NSK 5 reaching a Cronbach's alpha of .71, while removing NSK 2 and NSK 3. The reliability of social acceptance (SA) was measured per scenario (Cronbach's alpha between .81 and .94). We did not calculate an aggregated measure for the acceptance but kept them separate in the further analysis.

\subsection{Data analysis}

We used correlation analysis to check our hypotheses. Significant correlation coefficients can be found in Fig. 5 .

\subsubsection{User's background}

Our first research question was "Is there a relationship between the user characteristics and usefulness, attitude toward negotiation, behavioral control, and social acceptance". With regard to user characteristics, we only found a significant positive correlation between age and usefulness and a negative one between gender and usefulness. Computer skills and negotiation experience were not correlated with usefulness, attitude toward negotiation, or behavioral control. We removed the item education from the model, since our data were not heterogeneous enough to draw any conclusions on the effects of education level. We also removed nationality because the data were not equally distributed. Furthermore, the second set of research questions were "Is there a negative relationship between a person's attitude toward negotiations and the attitude toward NSS" and "Is there a relationship between, on the one hand, negotiation skills and experience and, on the other hand, the attitude toward negotiations". We did not find a significant correlation between a person's attitude toward negotiations and the attitude toward NSS. With regard to the second question, we found that negotiation skills are negatively correlated with the attitude toward negotiation opposing our initial hypothesis. However, negotiation skills were rated subjectively by the 
respondents themselves, which might not correspond to their actual negotiation skills. This issue needs further research.

\subsubsection{Usefulness, subjective norm, and social acceptance}

We found a positive correlation between usefulness and the attitude toward NSS, which confirms the relationship predicted by TAM. Considering our third research question "Is there a relationship between the social acceptance of an NSS and the intention to use it?" we can say the following. We found that social acceptance, (personal (SA 1) and opponent (SA 2) view), is correlated with the attitude toward NSS and the intention to use for all scenarios. However, when controlled for usefulness in the first case and subjective norm in the second, the correlations are either weaker or not significant. This suggests that the attitude toward an NSS is mainly influenced by how useful people consider it. The intention to use the system depends mainly on the subjective norm, i.e., whether others relevant to the respondent believe he or she should use it.

The dominance of subjective norm was further analyzed by regression analysis (Table 1) for each individual scenario. We used a stepwise method with the dependent variable intention to use NSS in a particular scenario and the following independent variables: attitude toward negotiation (NAT), behavioral control (BC), subjective norm (SN), and social acceptance (SA). Table 2 gives an overview of the regression models with included variables and coefficients. We can see that subjective norm has the major influence in predicting intention to use in all scenarios. In the car dealer scenario, it is even the only variable included in the model $(\beta=.58, t(118)=7.67$, $p<.001)$. In the collaborative preparation and the phone scenarios, behavioral control was also included in the model. In the face-to-face and the train scenario, behavioral control as well as social acceptance was included in the model. Whereas in face-to-face scenario, the social

Table 1 Results of regression analysis per scenario, $\mathrm{R}$ shows the strength of the relationship between the dependent variable and the independent variable(s)

\begin{tabular}{lllllllll}
\hline Scenario & $\mathrm{R}$ & $R^{2}$ & $\begin{array}{l}\text { Adj. } \\
R^{2}\end{array}$ & $\begin{array}{l}\text { SE (Std } \\
\text { error) }\end{array}$ & $d f_{\text {reg }}$ & $d f_{\text {res }}$ & $F$ & $P$ \\
\hline Train & .684 & .467 & .453 & 1.341 & 3 & 116 & 33.90 & $<.001$ \\
F-2-F & .762 & .580 & .569 & 1.143 & 3 & 116 & 53.39 & $<.001$ \\
$\begin{array}{l}\text { Coll. } \\
\text { preparation }\end{array}$ & .674 & .455 & .439 & 1.434 & 2 & 69 & 28.78 & $<.001$ \\
$\begin{array}{l}\text { Phone } \\
\text { Car dealer }\end{array}$ & .764 & .584 & .577 & 1.151 & 2 & 117 & 82.15 & $<.001$ \\
\hline
\end{tabular}

$R^{2}$ is the extent to which the independent variables can predict the dependent variable
Table 2 Estimated coefficients of regression models for each scenario, $\mathrm{B}$ and $\beta$ are the regression coefficients, unstandardized and standardized (same units), respectively

\begin{tabular}{|c|c|c|c|c|c|c|}
\hline Scenario & B & SE & $\beta$ & $t$ & $P$ & VIF \\
\hline \multicolumn{7}{|l|}{ Train } \\
\hline Constant & -.77 & .644 & & -1.19 & .24 & \\
\hline SN & .46 & .111 & .394 & 4.10 & $<.001$ & 2.01 \\
\hline BC & .38 & .126 & .237 & 3.04 & .003 & 1.33 \\
\hline SA & .22 & .105 & .188 & 2.11 & .04 & 1.73 \\
\hline \multicolumn{7}{|l|}{$F-2-F$} \\
\hline Constant & -1.25 & .523 & & -2.39 & .02 & \\
\hline SN & .52 & .097 & .441 & 5.33 & $<.001$ & 1.89 \\
\hline SA & .36 & .088 & .339 & 4.08 & $<.001$ & 1.91 \\
\hline $\mathrm{BC}$ & .24 & .095 & .157 & 2.56 & .01 & 1.04 \\
\hline \multicolumn{7}{|c|}{ Coll. preparation } \\
\hline Constant & -.41 & .794 & & -.51 & .61 & \\
\hline SN & .67 & .102 & .595 & 6.53 & $<.001$ & 1.05 \\
\hline $\mathrm{BC}$ & .34 & .144 & .215 & 2.36 & .02 & 1.05 \\
\hline \multicolumn{7}{|l|}{ Phone } \\
\hline Constant & -.37 & & & -.71 & .48 & \\
\hline SN & .82 & .076 & .704 & 10.88 & $<.001$ & 1.18 \\
\hline $\mathrm{BC}$ & .21 & .102 & .131 & 2.03 & .05 & 1.18 \\
\hline \multicolumn{7}{|c|}{ Car dealer } \\
\hline Constant & 1.01 & .383 & & 2.63 & .01 & \\
\hline SN & .70 & .092 & .577 & 7.67 & $<.001$ & 1.00 \\
\hline
\end{tabular}

VIF stands for variance inflation factor and measures the impact of collinearity among the variables

acceptance is the second strongest indicator before behavioral control, in the train scenario, it is the other way around. This is not surprising since in the situation with the boss social rules are much more important and can have stronger consequences than when sitting on a train. People using mobile devices on a train are a common sight, and therefore, social acceptance has less influence. More interesting is that in the other three scenarios, social acceptance is not included in the model. In the phone and collaborative preparation scenario, this might be due to the lack of a public setting.

Looking at the comments respondents gave voluntarily, we get deeper insight into how people see social acceptance considering the opponent's view in the different scenarios. People tend not to care whether the opponent accepts the NSS if they are not in eye contact ("This [on the phone] seems like the best application of the NSS, because it is invisible to the 'opponent'."). In the face-toface scenarios, people value the opponent's opinion highly. In the car dealer scenario, some respondents doubt the acceptance of the NSS by the opponent. However, usefulness, the competitive situation ("I think the opponent will accept it because otherwise people would go to the 
competitor".), or the ability to put pressure on the opponent ("I like the secret weapon!") causes people to care less about the opponent. In the job scenario between an employee and her boss, most respondents are worried about the opponent's opinion on the use of an NSS. The comments show different views considering not being honest ("I think it is not acceptable because she lies about using an NSS".), impolite ("It's very impolite to use an electronic device during a face-to-face negotiation".), embarrassed ("I would be embarrassed to use an NSS in this situation".), nervous ("Stealth mode would make me extremely nervous".), or appearing weak ("In a face-to- face negotiation, this would make you look like you cannot think for yourself"). A dominant opinion was that the interaction with the device will interrupt the communication flow ("The boss could get angry for not paying attention, the communication would be disturbed").

With regard to our last research question "Does the negotiation situation determine the social acceptance?", we found that the social acceptance, indeed, depends on the situation in which the NSS is used as shown in Fig. 6. Whereas most scenarios have an average rating above the scale's mean (4), the face-to-face situation with the boss got a low rating (3.06) lying significantly below the average $(t(119)=-6.25, p<.001)$. This means, in the latter scenario, people do not accept the use of an NSS. The situations that are most favorable for NSS use are negotiations on the phone and preparation on the train. At the car dealer or during the collaborative preparation, NSS are accepted, but the average rating is closer to the neutral value.

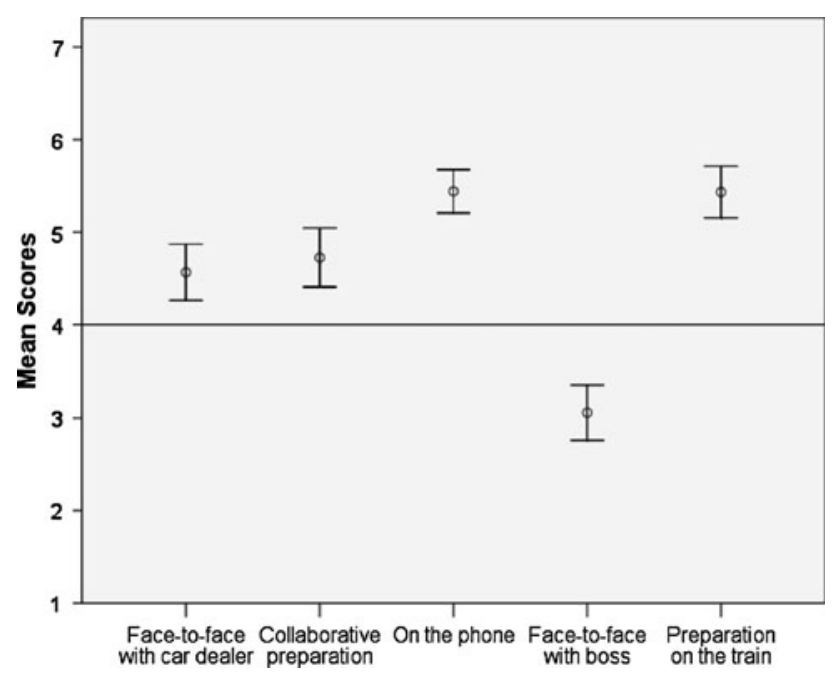

Fig. 6 Mean social acceptance ratings $(1=$ low to $7=$ high $)$

\subsection{Limitations}

The online survey presented has a few limitations. First of all, the participants were not offered the chance to interact with an implemented system. We used the TAM model because it is well known and a valid model to predict acceptance of new technology. We have to emphasize, however, that this model is based on constructs which can be perceived by the user when interacting with a real system. We are at the beginning of the development of a novel NSS. Therefore, no implementation was available. Furthermore, this study intended to inform the design process of a new NSS, instead of evaluating an existing design. To avoid misinterpretations, we excluded variables from the model that could not be perceived by only watching videos or seeing pictures, e.g., perceived ease of use. However, we would like to emphasize that we have to bear in mind that generally the added value a system can bring to the user's activity may strongly influence its acceptance. As ease of use was not measured and usefulness was not perceived directly by using the system, we cannot make general claims about this aspect. In our study, we focused rather on the use situations than the functionality the NSS could offer. We believe that by showing scenarios of use contexts in the questionnaire, we found a good way to give participants a vision of what the system could be able to do, but on such a level that it does not distract from the focus on the situation. We believe that people could get a feeling for the usefulness of the system and judge whether they would be able and willing to use it. The results of the survey pointed to social acceptance and subjective norm as major factors influencing the intention to use the NSS. There were only little indications (positive correlation between usefulness and attitude toward NSS) that people believed in the added value of the system. The fact that our hypothesis that people with less negotiation skills and negative attitudes toward negotiations would have a positive attitude toward the NSS could not be confirmed may signal that these people did not find the NSS particularly useful. In the user focus groups, the students were critical toward the presented NSS functionality in the different scenarios. While they had the opinion that it was only useful if people were not dependent on the system and if the advice was intelligent and comprehensible, they were positive toward using it as a trainer and to organize data. We believe that the issue of usefulness needs to be investigated in more detail with a follow-up study using first prototypes of the system.

Further limitations concern the number of participants in the survey and the opportunistic sample. Unfortunately, these aspects did not allow us to make any general claims about the acceptance of NSS with regard to cultural or educational backgrounds or differences depending on age 
groups. Despite this, we believe that we offer interesting results that put NSS into a different light. The fact that both subjective norm and situation dependency were major influential factors needs to be taken into consideration when designing new NSS, especially for mobile use.

\section{Design implications}

In the following section, we will point to several design implications resulting from the focus group discussions and the survey results.

\subsection{Implications from focus groups}

From the focus groups with negotiation experts, we could extract several themes, mostly focused on the functional requirements for a mobile NSS. In summary, the preparation phase of a negotiation and the actual negotiation with an opponent require different interaction styles. In the preparation phase, NSS should provide a negotiation training that is rich, content full, and contextual. Preferably, it should make use of an adaptive scenario including socially intelligent opponents to provide a real setting. During the negotiation with an opponent, on the contrary, the system should provide concrete, personalized advice regarding offers and generic advice regarding the negotiation process with easy interpretable hints. The interaction style in this case should be as little interrupting as possible.

The major implication of these guidelines is that NSS need to have intelligence and reasoning capabilities in order to process the information entered by the users and give personalized output. Furthermore, the system needs to possess an accurate user model that is updated during the interaction to be able to adapt to the user. Furthermore, the interaction styles need to be carefully selected for each phase of the negotiation.

Based on these themes, we constructed the following 12 design guidelines for NSS development (Pommeranz 2009):

1. An NSS should support interactive preparation sessions of different lengths.

2. The preparation module should have a simulation mode in which the user interacts with an intelligent negotiation agent.

3. The cognitive load of the information representation provided by the NSS during a face-to-face negotiation should be minimized.

4. In the training module, the user should be trained on being aware of the context.

5. Advice from an NSS should consider information about the context of the negotiation.
6. An NSS should support the user by calculating bids and offering new options to negotiate on.

7. It should have a data storing and managing function that gives the user easy access to the information needed at a certain point in time.

8. An NSS should generally provide the user with more generic advice that the user can apply to the situation he/she is in.

9. An NSS should be able to adapt to the user's skill level and experience and more in specific to the user's bidding behavior.

10. System advice should be based on the capabilities of the user to apply them in practice.

11. An NSS should suggest time-outs at appropriate stages in the negotiation process.

12. Partners should put in their preferences separately and assign an (emotional) value to each preference.

\subsection{Implications from social acceptance survey}

From the social acceptance survey, we learned that not only functionality and usefulness play a role, but also social aspects like the subjective norm and social acceptance. An NSS is not only a tool people use to fulfill a certain task, but also a social device depending on the use context. Therefore, the designer has to determine in which context the device should be used and fit the design to the context and its social norms. Furthermore, our survey has shown that the respondents value the opinions of close friends or family highly, both for deciding whether to use an NSS and when taking decisions during the negotiation. Some respondents mention explicitly that they consult others before an important negotiation. ("I would take others' opinions into consideration as well, [...]", "In buying something like a car [...] I get advice for prices online, from friends.") This behavior made us contemplate about the idea to create NSS that are connected to social networks. Friends using the same type of NSS could be connected to each other, and whenever one needs to take a decision, they could provide help or generally comment on each others' actions.

Another idea is storing negotiations within this network in a database that every NSS can access. This will enable users to see what strategies friends used in similar negotiations. These ideas fit social computing trends (Parameswaran and Whinston 2007) by bringing mobile information spaces to the user and using social networks to enhance the system's functionality. Also, if people like to ask friends for advice when negotiating, a good NSS should be designed to behave in a similar manner. Surely, there are more ways designers can think of to make NSS more social devices. 


\section{Conclusion}

We presented our steps in gathering requirements for the design of a new kind of mobile NSS including expert and user focus groups and an online survey aimed at determining the social acceptance of such a system. The focus groups were used to get a first impression of people's attitudes toward and functional wishes for mobile NSS. While we focused more on functional requirements in the expert focus groups (due to their negotiation expertise), the social acceptance in different use contexts became the main point in the user focus groups. The focus groups provided a lot of interesting qualitative data and gave first hints to which aspects were important for people and might lead to an acceptance of the system. We extracted 12 design guidelines for NSS from the qualitative data.

To support ideas from the focus groups and further investigate the concrete factors leading to an acceptance, we designed a questionnaire based on a NSS social acceptance model. We developed this model as a combination of the TAM and TPB models extended by a number of factors relevant specifically for NSS. With the help of the questionnaire, we collected data from 120 respondents with little negotiation experience in an online survey. We learned that when designing NSS, social issues cannot be neglected. Our survey shows that the use context of an NSS is an important factor influencing its social acceptance. The survey's respondents would not accept the use in face-toface situations when the relationship with the opponent was important, i.e., with one's boss. However, when the relationship is less important, i.e., with a car dealer, it is more accepted. In situations in which the opponent is not aware of the NSS, e.g., on the phone, it is most accepted. Surprisingly, the subjective norm is the most dominant factor influencing the intention to use a mobile NSS. People value opinions of their close ones highly when deciding whether to use an NSS and also ask them for advice when negotiating. Some implications of these results were mentioned (section design implications). However, we believe that there is far more room for designers to address these aspects in their designs in diverse ways.
We were able to obtain our results by giving people a vision of how a new kind of mobile NSS could be used by the help of filmed scenarios. This enabled us to inform the design process of our envisioned system in an early stage before first decisions and implementations have been made.

Our current work involves implementing a first prototype of a mobile NSS following the guidelines named above. The main focus lies on a good preparation for the negotiation by offering a preference elicitation interface that adapts to the users' needs and cognitive skills, as well as an interactive training with a virtual agent. Support throughout the different negotiation phases will be provided by a virtual coach, who behaves like a knowledgeable friend and reacts to the current context of the user. Ideas for connecting users of the NSS and store negotiation data in databases to be accessed by every user are left for future iterations of prototype development.

After implementing the prototype, we will be able to investigate more factors, which can only be perceived during the interaction with a running system, e.g., ease of use. Other aspects to be considered for future research are the influences of educational and cultural background of the user on attitudes toward negotiation and NSS.

Overall, when designing novel, mobile NSS we should aim for creating NSS not merely as tools but as social devices considering the use context and social networks.

Acknowledgments We would like to thank the negotiation experts, the participants of the focus groups, and the questionnaire respondents for valuable input. This research is supported by the Dutch Technology Foundation STW, applied science division of NWO and the Technology Program of the Ministry of Economic Affairs. It is part of the Pocket Negotiator project with grant number VICI-project 08075.

Open Access This article is distributed under the terms of the Creative Commons Attribution Noncommercial License which permits any noncommercial use, distribution, and reproduction in any medium, provided the original author(s) and source are credited.

\section{Appendix}

(Unless otherwise specified in the footnotes the answers were measured by a 7-point Likert scale).

See Table 3.

Table 3 A Questionnaire-English version

\begin{tabular}{ll}
\hline Item/construct & Question \\
\hline $\begin{array}{l}\text { Before all scenarios } \\
\text { GEN }\end{array}$ & What is your gender? (male/female) \\
COU & What is your nationality? (open) \\
EDU & What is your level of education? (No degree, vocational training, university degree) \\
AGE & How old are you? (open) \\
CSK (NEX) & How many hours do you spend using computers per week? (open) \\
\hline
\end{tabular}


Table 3 continued

\begin{tabular}{|c|c|c|}
\hline Item/construct & Question & Item included \\
\hline NEX 1 & How many houses have you sold? (open) & \\
\hline NEX 2 & How many houses have you bought? (open) & \\
\hline NEX 3 & How many job interviews have you had? (open) & \\
\hline NEX 4 & Is negotiation an important part of your job? (yes/no)) & \\
\hline \multicolumn{3}{|l|}{$(\mathrm{NAT})$} \\
\hline NAT 1 & Negotiation is a game & \\
\hline NAT 2 & I try to avoid negotiations & $*$ \\
\hline NAT 3 & I enjoy negotiations & $*$ \\
\hline NAT 4 (NSK) & Negotiations are a necessary must & \\
\hline NSK 1 & I am a good negotiator & $*$ \\
\hline NSK 2 & I would rather negotiate myself if the negotiation task is simple & \\
\hline NSK 3 & I would let someone else negotiate for me if the negotiation task is simple & \\
\hline NSK 4 & I would rather negotiate myself if the object of the negotiation is important for me & $*$ \\
\hline NSK 5 & I would let someone else negotiate for me if the object of the negotiation is important for me & * \\
\hline \multicolumn{3}{|c|}{ After each scenario } \\
\hline IU & I would use the Pocket Negotiator (PN) in the situation shown in the video/picture & \\
\hline SN (SA) & Most people who are important to me would think a Pocket Negotiator is useful in this situation & \\
\hline SA 1 & I think it is socially acceptable to use a PN in this situation & $*$ \\
\hline SA 2 & I think the opponent would think it is socially acceptable to use a PN in this situation & * \\
\hline \multicolumn{3}{|l|}{ Specific } \\
\hline Train & I expect a PN to prepare me in a short (1-2 hours) time before a negotiation & \\
\hline$f-2-f$ & A PN would be useful to propose new options for the negotiation & \\
\hline Coll.prep. & I expect a PN to help me organizing data (e.g., information from the internet) & \\
\hline Phone & I expect from a PN to give me a clear overview of the negotiation process & \\
\hline Car dealer & I believe the advice that the PN gives is useful for the negotiation & \\
\hline \multicolumn{3}{|l|}{ Comment } \\
\hline $\mathrm{COM}$ & Could you please explain what you based your ratings on? (open) & \\
\hline \multicolumn{3}{|c|}{ After all scenarios } \\
\hline PNA & My attitude toward using a $\mathrm{PN}$ is positive & \\
\hline \multicolumn{3}{|l|}{$\mathrm{BC}$} \\
\hline BC 1 & I would probably feel comfortable using a PN on my own & $*$ \\
\hline BC 2 & Learning to operate a PN would probably be easy for me & $*$ \\
\hline BC 3 & I would probably understand how to use a PN & $*$ \\
\hline \multicolumn{3}{|l|}{ USE } \\
\hline USE 1 & A PN would help me to reach a better outcome in a negotiation & $*$ \\
\hline USE 2 & I would feel more confident in the negotiation while using a PN & $*$ \\
\hline USE 3 & I will learn how to negotiate better through using the PN & $*$ \\
\hline USE 4 & Using a PN would increase my productivity & $*$ \\
\hline USE 5 & Using a PN would increase my negotiation performance & * \\
\hline USE 6 & Using a PN would enhance my effectiveness in negotiations & $*$ \\
\hline USE 7 & Using a PN would make negotiations easier for me & $*$ \\
\hline USE 8 & Overall, I find the PN useful for house/job negotiations & * \\
\hline OCM & Please feel free to enter comments here: (open) & \\
\hline
\end{tabular}

\section{References}

Ajzen I (1991) The theory of planned behavior. Organ Behav Hum Decis Process 50:179-211

Ajzen I, Fishbein M (1980) Understanding attitudes and predicting social behavior. Prentice-Hall, Englewood Cliffs
Bruseberg A, McDonagh-Philp D (2002) Focus groups to support the industrial/product designer: a review based on current literature and designers' feedback. Appl Ergon 33(1):27-381

Bui T (1994) Evaluating negotiation support systems: a conceptualization. In: Mudge TN, Shriver BD (eds) HICSS 1994, IEEE Press, New York 
Carey M (1995) Comment: concerns in the analysis of focus group data. Qual Health Res 5:487-495

Carroll J (2000) Making use: secenrio-based design of humancomputer interactions. MIT Press, Cambridge

Davis F (1989) Perceived usefulness, perceived ease of use, and user acceptance of information technology. MIS Q 13(3):319-339

Goodman J, Dickinson A, Syme A (2004) Gathering requirements for mobile devices using focus groups with older people. In: Designing a more inclusive world, Proceedings of the 2nd Cambridge Workshop on Universal Access and Assistive Technology (CWUAAT). Springer, Berlin

Havard Business School Essentials: (2003) Negotiation. Harvard Business School Publishing Corporation, Boston

Hindriks K, Jonker C (2008) Creating human-machine synergy in negotiation support systems: towards the pocket negotiator. In: Brinkman W-P, Hindriks K (eds) HuCom'08, ACM, New York

ITU (2004) Itu internet reports: the portable internet, http://www.itu.int./portableinterne. Tech rep, ITU

Kersten G (1999) Negotiation support systems and negotiating agents. In: Modles et Systmes Multi-Agents pour la Gestion de la Environement et des Territoire

Kersten G (2004) E-negotiation systems: interaction of people and technologies to resolve conflicts. Interneg Research Papers INR 08/04:1-21

Kersten G, Lo G (2003) Aspire: an integrated negotiation support system and software agents for ebusiness negotiation. Int J Inter Enterprise Manag 1(2):293-315

Kersten HG, Lai E (2007) Negotiation support and e-negotiation systems: an overview. Group Decision Negotiation 16:553-586

Ling R (1997) One can talk about common manners!: the use of mobile telephones in inappropriate situations. in themes in mobile telephony. In: Haddon L (ed) Themes in mobile telephony final report of the COST 248 Home and Work group

Love S, Perry M (2004) Dealing with mobile conversations in public places: some implications for the design of socially intrusive technologies. In: CHI'04. ACM, New York, pp 1195-1198

Mallat N, Rossi M, Tuunainen V, Arni A (2009) The impact of use context on mobile services acceptance: the case of mobile ticketing. Inform Manag 46:190-195

Neerincx M (2003) Cognitive task load design: model, methods and examples. In: Hollnagel E (ed) Handbook of cognitive task design. chapter 13. Lawrence Erlbaum Associates, Mahwah

Nunamaker JF, Briggs RO, Mittleman D (1996) Lessons from a decade of group support systems. In: Proc of the twenty-ninth Hawaii international conference on system sciences 1996, vol. 3 , pp. $418-427$
Palen L, Salzman M, Youngs E (2001) Discovery and integration of mobile communications in everyday life. Personal Ubiquitous Comput 5(2):109-122

Parameswaran M, Whinston A (2007) Social computing: an overview. Commun Assoc Inf Syst 19:762-780

Pommeranz A, Brinkman WP, Wiggers P, Broekens J, Jonker CM (2009) Towards design guidelines for negotiation support systems: an expert perspective using scenarios. In: Proc ECCE'09, VTT, Finland, pp 271-278

Pommeranz A, Brinkman WP, Wiggers P, Jonker CM (2010) Social acceptance of negotiation support systems. In: Proc USAB 2010, Springer, Berlin

Rangaswamy A, Shell G (1997) Using computers to realize joint gains in negotiations : towards an electronic bargaining table. Manag Sci 43(8):1147-1163

Schoop M, Jertila A, List T (2001) Negoisst: a negotiation support system for electronic business-to-business negotiations in e-commerce. Data Knowl Eng 47(3):371-401

Shih H (2004) Extended technology acceptance model of internet utilization behavior. Inform Manag 41(6):719-729

Sim J (2001) Collecting and analysing qualitative data: issues raised by the focus group. J Adv Nurs 28(2):345-352

Smith J, Osborn M (2003) Interpretative phenomenological analysis. In: Qualitative Psychology: A Practical Guide to Methods. Sage, London

Srivastava L (2005) Mobile phones and the evolution of social behavior. Behav Inform Technol 24(2):111-129

Swaab R, Postmes T, Neijens P (2004) Negotiation support systems: communication and information as antecedents of negotiation settlement. Int Negotiation 9:59-78

Thomson L (2005) The heart and mind of the negotiator. Pearson Prentice Hall, New Jersey

Vetschera R, Kersten G, Koeszegi S (2006) User assessment of internet-based negotiation support systems: an exploratory study. J Organ Comput E-Commerce 16(2):123-132

Wang W, Benbasat I (2005) Trust in and adoption of online recommendation agents. J Assoc Inform Syst 6(3):72-101

Wixom BH, Todd PA (2005) A theoretical integration of user satisfaction and technology acceptance. Inform Syst Res 16(1):85-102

Yu JLC, Liu C, Yao JE (2003) Technology acceptance model for wireless internet. Intern Res 13(3):206-222 